Received: 24 February 2019, Revised: 10 March 2019 Accepted: 3 April 2019, Published: 28 April 2019

Available online at: http://e-journal.unair.ac.id/index.php/IMHSJ

\title{
HUBUNGAN TINGKAT PENDIDIKAN DENGAN KEPATUHAN ANTENATAL CARE PADA PRIMIGRAVIDA RIWAYAT PERNIKAHAN DINI
}

\section{RELATIONSHIP LEVEL OF EDUCATION WITH ANTENATAL CARE COMPLIANCE IN PRIMIGRAVIDA WITH EARLY MARRIAGE HISTORY}

\author{
Nur Indah Dwi Yanti ${ }^{1}$, Ilya Krisnana ${ }^{2}$, Pudji Lestari ${ }^{3}$ \\ ${ }^{1}$ Program Studi Kebidanan Fakultas Kedokteran Universitas Airlangga \\ ${ }^{2}$ Departemen Keperawatan Maternitas dan Anak Fakultas Keperawatan \\ Universitas Airlangga \\ ${ }^{3}$ Departemen Ilmu Kesehatan Masyarakat Fakultas Kedokteran Universitas \\ Airlangga \\ Alamat korespondensi: \\ Jalan Semolowaru 34 Surabaya, Indonesia \\ Email:nurindah.dwi49@gmail.com
}

\begin{abstract}
Abstrak
Latar Belakang: Pernikahan dini merupakan salah ssatu masalah kesehatan reproduksi di Indonesia. Berdasarkan laporan BPS 2017 angka pernikahan dini di Indonesia mencapai 25,71\%, sedangkan di Kabupaten jember 28,66\% perempuan menikah di usia dini. Antenatal care yang rutin dapat menurunkan angka kematian ibu. Berdasarkan Kemenkes 2017 kehamilan pada ibu dibawah usia 20 tahun meningkatkan angka kematian ibu. Remaja perempuan yang telah menikah cenderung 11 kali memiliki pendidikan yang rendah. Penelitian ini bertujuan untuk menganalisis hubungan tingkat pendidikan dengan kepatuhan antenatal care pada ibu hamil primigravida dengan riwayat pernikahan dini. Metode: Metode penelitian ini adalah penelitian cross sectional. Instrument yang digunakan adalah kuesioner. Analisis data menggunakan uji chi square dengan $\alpha=0,05$. Hasil: Hasil penelitian menunjukkan $81,35 \%$ ibu hamil dalam kategori usia remaja akhir, 54,2\% Ibu hamil memiliki pendidikan terakhir SMP, Ibu hamil yang patuh dalam ANC sebesar 64,4\%, ibu hamil dengan pendidikan SMA patuh dalam ANC (70,5\%) dan didapatkan nilai $p=0,005$. Kesimpulan: Data tersebut menunjukkan bahwa terdapat hubungan antara tingkat pendidikan dengan kepatuhan ANC pada ibu hamil dengan riwayat pernikahan dini di Kecamatan Tanggul Kabupaten Jember.
\end{abstract}

Kata kunci: Tingkat pendidikan, Kepatuhan antenatal care, Pernikahan dini

\section{Abstract}

Background: Early marriage is one of the reproductive health problems in Indonesia. Based on the BPS report 2017 the rate of early marriage in Indonesia reached $25.71 \%$, while in Kabupaten Jember $28.66 \%$ of women married at an early age. Regular antenatal care can reduce maternal mortality. Based on the Ministry of Health 2017 under 20 years of gestation increases maternal mortality. Married girls tend to have 11 times lower education. This study aims to analyze the relationship of education with the agreement of antenatal care in primigravida pregnant women with a collection of early marriage. Method: The method of this study is a cross-sectional study. The instrument used was a questionnaire. Data analysis using chi square test with $\alpha=0.05$. Results: The results showed $81.35 \%$ of pregnant women in the final adolescent age category, $54.2 \%$ of pregnant women had the last junior high school education, $64.4 \%$ of obedient pregnant women in the ANC, pregnant women with high school education were obedient in the ANC $(70,5 \%)$ and the value of $p=0.005$ is obtained. Conclusion: The data shows that there is a relationship between 
education level and ANC compliance in pregnant women with a history of early marriage in the Tanggul District of Jember Regency.

Keywords: Level of education, Antenatal care compliance, Early marriage

\section{PENDAHULUAN}

Perawatan antenatal care merupakan upaya preventif program pelayanan kesehatan obstetrik untuk optimalisasi luaran maternal dan neonatal melalui serangkaian kegiatan pemantauan rutin selama kehamilan (Prawirohardjo, 2014). Setiap ibu hamil mempunyai risiko terhadap komplikasi yang mengancam nyawanya. Oleh karena itu, setiap ibu hamil perlu setidaknya empat kali pemeriksaan kehamilan ke fasilitas kesehatan selama masa kehamilannya (Manuaba et al., 2012; Kemenkes RI, 2017a).

pernikahan dini adalah pernikahan yang dilakukan dibawah usia 20 tahun (BKKBN, 2010). Berdasarkan data BKKBN 2015 usia kawin pertama penduduk wanita $<20$ tahun sebesar 53 per 1000 remaja (DPPA and BKKBN, 2018; Priohutomo, 2018). Sedangkan menurut laporan BPS 2017, angka pernikahan dini di Indonesia mencapai 25,71\%. Berdasarkan laporan pernikahan tahun 2018, Kecamatan Tanggul menempati angka tertinggi untuk pernikahan dibawah usia 20 tahun yaitu sebesar $73 \%$ atau sejumlah 444 wanita, dengan cakupan pelayanan kunjungan (K4) ibu hamil sebesar 60,04\% di Puskesmas Klatakan dan 97,1\% di Puskesmas Tanggul (Dinas Kesehatan Jember, 2017; DPPA and BKKBN, 2018).

Penelitian di beberapa daerah menyebutkan perkawinan dini meningkatkan risiko preeklampsia, ruptur uteri, dan HIV/AIDS. Menikah di usia muda berisiko tidak siap untuk menerima kehamilan, melahirkan dan merawat anak, sehingga berpotensi untuk melakukan aborsi yang tidak aman yang menyebabkan kematian ibu dan bayi (Kartikawati, 2014). Kehamilan pada ibu di bawah usia 20 tahun memiliki kontribusi dalam tingginya angka kematian maternal serta neonatal, bayi, dan balita (Kemenkes RI, 2017c). Kematian maternal dapat dicegah dengan tindakan yang tepat seperti antenatal care (Rashad and Essa, 2010).

Salah satu faktor yang mempengaruhi perilaku sesorang untuk memanfaatkan pelayanan kesehatan berdasarkan teori Lawrence Green (1948) yaitu faktor predisposisi (predisposing factors), yang terwujud dalam pendidikan yang dapat mendorong ibu hamil melakukan perawatam kehamilan (Notoadmodjo, 
2012). Penelitian yang dilakukan oleh Rachmawati et al (2017) menunjukkan bahwa peningkatkan tingkat pendidikan akan menghasilkan perilaku perawatan kehamilan yang lebih baik. Ibu hamil yang dengan tingkat pendidikan lebih tinggi, mempunyai pemahaman lebih tentang masalah kesehatan sehingga mempengaruhi sikap mereka terhadap kehamilan termasuk dalam melakukan antenatal care (Notoadmodjo, 2012b; Hagey, Rulisa and Pérez-Escamilla, 2014). Namun remaja perempuan yang telah menikah cenderung memiliki tingkat pendidikan yang lebih rendah. Sebuah laporan menyebutkan, 85 persen anak perempuan Indonesia mengakhiri pendidikan mereka setelah menikah. Disamping itu, beberapa sekolah menolak anak yang telah menikah untuk bersekolah (Badan Pusat Statistik, 2015). Berdasarkan penelitian sebelumnya, remaja yang menikah dibawah 20 tahun cenderung mengakhiri pendidikannya sehingga memiliki pendidikan yang lebih rendah (Priohutomo, 2018).

Tujuan dari penelitian ini yaitu menganalisis hubungan tingkat pendidikan dengan kepatuhan antenatal care pada ibu hamil primigravida dengan riwayat pernikahan dini di Kecamatan Tanggul Kabupaten Jember. Hipotesis penelitian ada hubungan tingkat pendidikan dengan kepatuhan antenatal care pada ibu hamil primigravida dengan riwayat pernikahan dini di Kecamatan Tanggul Kabupaten Jember.

\section{METODE}

Rancangan penelitian yang digunakan adalah analitik obeservasional dengan rancangan penelitian cross sectional. Populasi pada penelitian ini adalah seluruh ibu hamil primigravida dengan riwayat pernikahan dini yang berada di Kecamatan Tanggul Kabupaten Jember dengan jumlah 59 ibu hamil. Teknik sampel yang digunakan adalah total sampling, besar sampel yang didapatkan yaitu 59 responden.

Variabel bebas dalam penelitian ini adalah tingkat pendidikan. Variabel terikat adalah kepatuhan antenatal care berskala data nominal. Instrumen yang digunakan adalah kuesioner. Parameter kepatuhan antenatal care yaitu patuh jika melakukan kunjungan minimal trimester I: 1 kali, trimester II: 1 kali dan trimester III: 2 kali, tidak patuh jika tidak melakukan kunjungan sama sekali sesuai usia 
kehamilan atau frekuensi minimal sesuai usia kehamilan tidak tercapai (Kemenkes RI, 2017a)

Pengumpulan data dilakukan pada bulan April - Mei 2019 dimulai dengan penentuan sampel penelitian. Pengumpulan data dari responden dilakukan dengan wawancara melalui kunjungan rumah dan Posyandu. Pengolahan data dilakukan dengan editing, coding, entry, cleaning, dan tabulating data. Data yang sudah terkumpul dan diolah kemudian dianalisis menggunakan uji chi square dengan bantuan program komputer SPSS.

\section{HASIL DAN PEMBAHASAN}

Hasil penelitian menunjukkan bahwa hampir seluruh responden $(81,35 \%)$ berada dalam kategori remaja akhir yaitu dalam rentang usia 17 sampai 19 tahun. Sebagian besar responden $(54,2 \%)$ menempuh pendidikan terakhir sampai sekolah menengah pertama. Sedangkan ibu hamil yang patuh dalam kunjungan antenatal care (ANC) sebesar 64,4\%.

\section{Tabel 1 Karakteristik responden}

\begin{tabular}{llll}
\hline \multirow{2}{*}{ Karakteristik } & \multirow{2}{*}{ Kategori } & Frekuensi & \\
\cline { 3 - 4 } Umur & Remaja Awal (10-14 tahun) & 1 & $\mathbf{\%}$ \\
& Remaja Tengah (15-16 tahun) & 5 & 1,69 \\
& Remaja Akhir (17-19 tahun) & 48 & 8,47 \\
& Dewasa ( $\geq 20$ tahun) & 5 & 81,35 \\
Total & & 59 & 8,47 \\
Pendidikan & SD & 10 & 100 \\
& SMP & 32 & 16,9 \\
& SMA & 17 & 54,2 \\
Total & & 59 & 28,8 \\
\hline
\end{tabular}

Hasil penelitian ini menunjukkan bahwa hampir seluruh ibu hamil yang memiliki pendidikan terakhir menengah atas (SMA) $(76,5 \%)$ patuh dalam melakukan kunjungan antenatal care (ANC), sedangkan hampir seluruh ibu hamil dengan pendidikan dasar (SD) (80\%) tidak patuh melakukan ANC. 
Indonesian Midwifery and Health Sciences Journal

Tabel 2 Analisis hubungan pendidikan dengan kepatuhan ANC pada ibu dengan riwayat pernikahan dini

\begin{tabular}{|c|c|c|c|c|c|c|}
\hline \multirow[b]{2}{*}{ Pendidikan } & \multicolumn{2}{|c|}{ Patuh ANC } & \multicolumn{2}{|c|}{ Tidak Patuh ANC } & \multicolumn{2}{|l|}{ Total } \\
\hline & Jumlah & $\%$ & Jumlah & $\%$ & Jumlah & $\%$ \\
\hline SD & 2 & 20 & 8 & 80 & 10 & 100 \\
\hline SMP & 24 & 75 & 8 & 25 & 32 & 100 \\
\hline SMA & 12 & 70,5 & 5 & 29,5 & 17 & 100 \\
\hline
\end{tabular}

Analisis statistik yang digunakan untuk menguji hubungan antara status pendidikan dengan kepatuhan $\mathrm{ANC}$ adalah uji Chi square menggunakan taraf kepercayaan 95\%. Hasil dari uji statistik didapatkan nilai signifikansi $(p)$ sebesar 0,005. Nilai tersebut lebih kecil dibandingkan dengan $\alpha(0,05)$, sehingga $\mathrm{H}_{0}$ ditolak. Kesimpulan yang didapat yaitu ada hubungan antara pendidikan dengan kepatuhan ANC pada ibu hamil dengan riwayat pernikahan dini.

Hasil penelitian menggunakan uji Chi square menunjukkan bahwa terdapat hubungan antara tingkat pendidikan dengan kepatuhan ANC pada ibu hamil primigravida dengan riwayat pernikahan dini. Hasil penelitian menunjukkan ibu hamil dengan riwayat pernikahan dini sebagian besar masih memiliki pendidikan terakhir SMP/sederajat, sebagian kecil tamat SD/sederajat dan sisanya tamat SMA/sederajat. Hal ini sesuai dengan laporan BPS (2015) bahwa remaja perempuan yang telah menikah, cenderung memiliki tingkat pendidikan yang lebih rendah. Pendidikan dianggap bertentangan dengan pernikahan, ketika perempuan yang menikah mengalami kehamilan dan tanggung jawab terhadap perawatan anak. Penelitian kepada ibu hamil remaja di Lesotho didapatkan remaja perempuan yang menikah cenderung dengan suami yang juga memiliki pendidikan rendah dan suami akan melarang istri untuk kembali ke sekolah. Remaja hamil juga akan malu kembali ke sekolah sebagai wanita yang sudah berstatus menikah (Phafoli et al., 2014).

Ibu hamil dengan pendidikan SMA, hampir seluruhnya patuh dalam ANC, sedangkan ibu yang memiliki pendidikan SD hanya sebagian kecil yang patuh dalam ANC. Hasil penelitian ini sejalan dengan penelitian yang dilakukan oleh Wulandatika (2017), dimana pendidikan merupakan faktor dominan yang berhubungan dengan ANC, ibu hamil dengan pendidikan tinggi 3 kali lebih patuh 
dibandingkan ibu hamil dengan pendidikan rendah. Selain itu penelitian lain juga menyebutkan bahwa ada hubungan antara pendidikan dengan kepatuhan ANC pada ibu hamil di Puskesmas Gayaman Mojokerto dengan nilai (Sari and Efendy, 2017).

Terdapat sebagian kecil ibu hamil dengan pendidikan rendah (SD) yaitu 2 orang yang patuh dalam ANC, hal ini dapat terjadi karena faktor lain yang mendorong ibu untuk patuh dalam ANC. Sebaliknya ibu dengan pendidikan terakhir SMA, sebagian kecil tidak patuh dalam ANC, dikarenakan kemungkinan terdapat faktor lain yang menghambat ibu untuk melakukan kunjungan ANC. Angka kepatuhan ANC pada responden yaitu 64,4\% masih tergolong rendah, dimana target nasional untuk program $\mathrm{K} 1=91 \%$ dan program $\mathrm{K} 4$ sebesar $80 \%$ (Kemenkes RI, 2017b).

Hasil penelitian ini sesuai dengan teori Notoadmodjo (2012) yang menyatakan bahwa tingkat pendidikan yang lebih tinggi dapat menambah pemahaman seseorang sehingga mempengaruhi perilaku, dalam hal ini kepatuhan kunjungan ANC. Tingkat pendidikan dapat mempengaruhi tingkat paparan dan aksesibilitas seseorang terhadap informasi kesehatan (Kasim et al., 2016). Semakin tinggi tingkat pendidikan, maka ibu hamil dapat mencari informasi lebih baik khususnya dalam hal kesehatan sehingga ibu dapat memahami kondisi kesehatannya, begitupula sebaliknya. Apabila ibu mengetahui banyak informasi tentang pentingnya patuh dalam ANC, maka ibu akan mengetahui cara menurunkan risiko pada kehamilan, salah satunya dengan patuh memeriksakan kehamilan (Mantao and Suja, 2018). Pendidikan yang dimiliki oleh ibu dapat mempengaruhi ibu untuk bertindak dalam mencari penyebab dan solusi dalam hidupnya, serta lebih mengerti tentang pentingnya kunjungan antenatal care (Ulaa, 2017). Heriani (2017) menyatakan bahwa tingkat pendidikan dapat menunjukkan status kesehatan seseorang, karena pendidikan merupakan faktor penting yang mempengaruhi ibu dalam menghadapi kehamilan dan persalinan. Hal ini membuktikan bahwa ibu hamil yang menikah dini cenderung memiliki pencapaian pendidikan yang lebih rendah sehingga tidak patuh dalam melakukan ANC.

Tingkat pendidikan perempuan yang lebih tinggi dapat meningkatkan pendapatan, mengurangi kesenjangan gender serta dapat memberdayakan perempuan (Joshi et al., 2014). Pendidikan dapat memupuk nilai-nilai dan sikap 
yang baru, sehingga memberdayakan perempuan untuk mengakses antenatal care (Furuta and Salway, 2016). Pendidikan yang lebih tinggi dapat mempermudah ibu dalam menerima informasi terkait perawatan kehamilan. Oleh karena itu, diperlukan kebijakan yang bertujuan meningkatkan pendidikan perempuan yang juga akan meningkatkan kepatuhan ANC dan mengurangi angka pernikahan dini. Hal ini sangat penting, karena di Indonesia kewajiban sekolah hanya sampai 9 tahun atau sampai SMP dan sebagian besar dari ibu yang menikah dini di Kecamatan Tanggul juga masih memiliki pendidikan tingkat SMP.

\section{SIMPULAN DAN SARAN}

Terdapat hubungan antara tingkat pendidikan dengan kepatuhan antenatal care, ibu dengan tingkat pendidikan yang lebih tinggi lebih patuh dalam melakukan kunjungan antenatal care.

Ibu hamil terutama yang berusia $<20$ tahun sebaiknya lebih rutin untuk melakukan antenatal care dan bagi Puskesmas untuk dapat memberikan pendidikan terkait pentingnya antenatal care terutama pada ibu dengan pernikahan dini.

\section{DAFTAR PUSTAKA}

Badan Pusat Statistik (2015) Kemajuan yang Tertunda : Analisis Data Perkawinan Usia Anak di Indonesia. Jakarta: Badan Pusat Statistik dan UNICEF.

BKKBN (2010) Pendewasaan Usia Perkawinan Dan Hak-hak Reproduksi Bagi Remaja Indonesia. Edisi II. Jakarta: Badan Koordinasi Keluarga Berencana Nasional.

Dinas Kesehatan Jember (2017) Profil Kesehatan Kabupaten Jember Tahun 2016. Jember. Available at: http://www.depkes.go.id/resources/download/profil/PROFIL_KAB_KOT A_2016/3509_Jatim_Kab_Jember_2016.pdf.

DPPA and BKKBN (2018) Laporan Pernikahan Berdasarkan Umur Istri. Jember. Furuta, S. and Salway, S. (2016) 'Women's Position WIthin The Household as a Determinant of Maternal Health Care Use in Nepal', Int Fam Plan Perspect, 32(1), pp. 17-27.

Hagey, J., Rulisa, S. and Pérez-Escamilla, R. (2014) 'Barriers and solutions for timely initiation of antenatal care in Kigali, Rwanda: Health facility professionals' perspective', Midwifery. Elsevier, 30(1), pp. 96-102.

Heriani (2017) 'Kecemasan dalam Menjelang Persalinan Ditinjau dari Paritas, Usia dan Tingkat pendidikan', Jurnal Aisyah: Jurnal Ilmu Kesehatan, 1(2), pp. 01-08.

Joshi, C. et al. (2014) 'Factors associated with the use and quality of antenatal care 
in Nepal: a population-based study using the demographic and health survey data', BMC pregnancy and childbirth. BioMed Central, 14(1), p. 94. Available at: https://bmcpregnancychildbirth.biomedcentral.com/articles/10.1186/14712393-14-94\#Bib1.

Kartikawati, R. (2014) 'Dampak Perkawinan Anak di Indonesia', Jurnal Studi Pemuda, 3(1), pp. 1-16.

Kasim, R. et al. (2016) 'Knowledge, attitudes and practice of preconception care among women attending maternal health clinic in Kelantan', Education in Medicine Journal, 8(4).

Kemenkes RI (2017a) Profil Kesehatan Indonesia. Jakarta: Kemenkes RI. Available at: http://www.depkes.go.id/resources/download/pusdatin/profilkesehatan-indonesia/Profil-Kesehatan-Indonesia-tahun-2017.pdf.

Kemenkes RI (2017b) Profil Kesehatan Provinsi Sumatera Barat 2017. Sumatera barat. Available at: http://www.depkes.go.id/resources/download/profil/PROFIL_KES_PROV INSI_2017/03_Sumbar_2017.pdf.

Kemenkes RI (2017c) Risiko Hamil Di Usia Remaja, Depkes RI. Available at: http://www.depkes.go.id/article/print/17100200001/inilah-risiko-hamil-diusia-remaja.html (Accessed: 1 March 2019).

Mantao, E. and Suja, M. D. . (2018) 'Tingkat Pendidikan Ibu dengan Kepatuhan Antenatal Care Pada Perdesaan dan Perkotaan di Indonesia', Berita Kedokteran Masyarakat Universitas Gadjah Mada. Yogyakarta: Public Health Universitas Gadjah Mada, 34(5). Available at: https://jurnal.ugm.ac.id/bkm/article/view/37405.

Manuaba, I. G. . et al. (2012) Pengantar Kuliah Obstetri. Jakarta: EGC.

Notoadmodjo, S. (2012) Promosi Kesehatan dan Perilaku Kesehatan. Jakarta: Rineka Cipta.

Phafoli, S. et al. (2014) 'Variables Influencing Delay in Antenatal Clinic Attendance Among Teenagers in Lesotho', SA Farm Pract, 49(9), p. 17.

Prawirohardjo, S. (2014) Ilmu Kebidanan. Jakarta: Yayasan Bina Pustaka Sarwono Prawirohardjo.

Priohutomo, S. (2018) Mencegah pernikahan anak melalui program kkbpk. Banjarmasin. Available at: https:/www.bkkbn.go.id/pocontent/uploads/2018.03.10.Banjarmasin.MENCEGAH_PERKAWINAN_ ANAK_MEL_PROG_KKBPK.pdf.

Rachmawati, A. I. et al. (2017) 'Faktor-faktor yang Memengaruhi Kunjungan Antenatal Care (ANC) Ibu Hamil Factors Affecting The Antenatal Care ( ANC ) Visits on Pregnant Women', Universitas Lampung, 7(November), pp. $72-76$.

Rashad, W. A. and Essa, R. M. (2010) 'Women' s Awareness of Danger Signs of Obstetrics Complications', Journal of American Science, 6(11), pp. 802809.

Sari, K. I. . and Efendy, H. . (2017) 'Analisis Faktor yang Berpengaruh Terhadap Kunjungan Antenatal Care', Jurnal Keperawtan dan Kebidanan, 9(1), pp. 93-113. Available at: http://jurnalonline.lppmdianhusada.ac.id/index.php/jkk/article/view/108.

Ulaa, M. (2017) 'Hubungan Usia Dan Tingkat Pendidikan Dengan Kepatuhan Ibu 
Hamil Melakukan Kunjungan Antenatal Care', Proceeding Seminar Nasional Keperawatan. Proceeding Seminar Nasional Keperawatan, (Vol 3, No 1 (2017): Proceeding Seminar Nasional Keperawatan 2017), pp. 238243. Available

at: http://conference.unsri.ac.id/index.php/SNK/article/view/777.

Wulandatika, D. (2017) 'Faktor-Faktor Yang Berhubungan Dengan Kepatuhan Ibu Dalam Melakukan Kunjungan Antenatal Care Di Wilayah Kerja Puskesmas Gambut Kabupaten Banjar, Kalimantan Selatan Tahun 2013', Jurnal Ilmu Keperawatan dan Kebidanan, 8(2), pp. 8-18. doi: 10.26751/jikk.v8i2.269. 